\title{
Advanced imaging in acute stroke management-Part I: Computed tomographic
}

\author{
Monica Saini, Ken Butcher \\ Stroke Unit, Division of Neurology, University of Alberta, Canada
}

\author{
Address for correspondence: \\ Dr. Monica Saini, \\ Division of Neurology, University \\ of Alberta 84-1120, Edmonton, \\ Alberta, T6G2R4, Canada \\ E-mail: sainimmm@gmail.com
}

PMID: 19934551

DOI: $10.4103 / 0028-3886.57791$

\begin{abstract}
Neuroimaging is fundamental to stroke diagnosis and management. Non-contrast computed tomography (NCCT) has been the primary imaging modality utilized for this purpose for almost four decades. Although NCCT does permit identification of intracranial hemorrhage and parenchymal ischemic changes, insights into blood vessel patency and cerebral perfusion are limited. Advances in reperfusion strategies have made identification of potentially salvageable brain tissue a more practical concern. Advances in CT technology now permit identification of acute and chronic arterial lesions, as well as cerebral blood flow deficits. This review outlines principles of advanced CT image aceuisition and its utility in acute stroke management.
\end{abstract}

Key words: Computed tomography, computed tomographic angiography, hemorrhagic stroke, ischemic stroke, perfusion computed tomography

\section{Introduction}

Imaging of the brain parenchyma is critical to differentiate hemorrhagic stroke from ischemic stroke and also to rule out other structural causes which can present as stroke mimics. In the early 1970s, computed tomographic (CT) scanners made their appearance and have since become the main diagnostic tool in acute stroke..$^{[1]}$ Recent advances in CT technology provide the means to differentiate salvageable from the irreversibly damaged brain tissue and also to identify pathphysiological mechanisms (vascular occlusion or stenosis) of stroke. Thrombolysis trials make it clear that rapid diagnosis, with minimal delay in treatment is essential. ${ }^{[2]}$ Although advanced CT imaging does add to the total imaging time, the ability to visualize markers of the ischemic penumbra may permit more patientand pathophysiology-specific treatment.

\section{The Ischemic Penumbra}

In acute ischemic stroke, arterial occlusion results in a reduction in cerebral blood flow $(\mathrm{CBF})$. The reduction in $\mathrm{CBF}$ varies regionally, within the distribution of the affected artery. The ischemic penumbra was first described as that tissue between an upper CBF threshold of electrical silence and a lower flow threshold of ion pump failure resulting in loss of cellular membrane integrity. ${ }^{[3]}$ In simpler terms, the penumbra is the hypoperfused, hypoxic tissue that is structurally intact, at risk of infarction but potentially salvageable with early reperfusion. Tissue which is irreversibly injured is referred to as the infarct core. With increasing time to reperfusion, the infarct core expands to include the penumbral tissue. Neurological outcomes after stroke correlate with penumbral tissue salvage; the current therapeutic strategies for acute stroke are, therefore, aimed at preservation of penumbral tissue and arresting its transition to infarction. The ideal imaging technique should be able to distinguish patients with penumbra, who will benefit from recanalization, from those who do not have salvageable tissue, and may indeed be at risk for hemorrhage following thrombolytic therapy.

\section{Imaging the Parenchyma: Non-contrast Computed Tomography}

Early ischemic changes (EIC) in brain parenchyma 
seen on non-contrast CT (NCCT) include focal swelling (sulcal effacement) and hypoattenuation. ${ }^{[4]}$ We define hypoattenuation as loss of differentiation of the grey matter from adjacent white matter, and hypodensity as decrease in tissue density below that of normal white matter [Figure1]. The sensitivity of NCCT for ischemia is time-dependent; in the first $3 \mathrm{~h}$, it is less than $50 \%$ and increases to $80-90 \%$ at 6 h. ${ }^{[5,6]}$ For the diagnosis of lacunar infarcts within the first $6 \mathrm{~h}$, the sensitivity is less than $50 \% .{ }^{[7]}$ There is evidence that ischemic changes influence the response to reperfusion therapy, probability of hemorrhagic transformation and the clinical outcome after stroke. ${ }^{[8-10]}$

The European Cooperative Acute Stroke Study (ECASS) trials first utilized the extent of early ischemic changes on CT as exclusion criteria for thrombolytic therapy. ${ }^{[11]}$ Results from the ECASS I trial showed that focal hypodensity, as seen on baseline CT, was associated with early stroke progression (neurological deterioration within first $24 \mathrm{~h}$ of stroke onset). ${ }^{[12]}$ Retrospective analysis of ECASS data showed that in patients with evidence of hypoattenuation involving $<33 \%$ middle cerebral artery (MCA) territory early intravenous activated tissue plasminogen (IV-tPA) had a therapeutic benefit. In patients with hypoattenuation in $>33 \%$ of the MCA territory, however, IV-tPA was associated with an increased risk of hemorrhage and no therapeutic benefit. ${ }^{[1]}$ Based on this data, the ECASS investigators formulated the "one-third MCA" rule, which was used to define major infarction (hypoattenuation or cerebral edema involving $>33 \%$ of the MCA territory); patients with CT changes of major infarction did not qualify for thrombolysis.

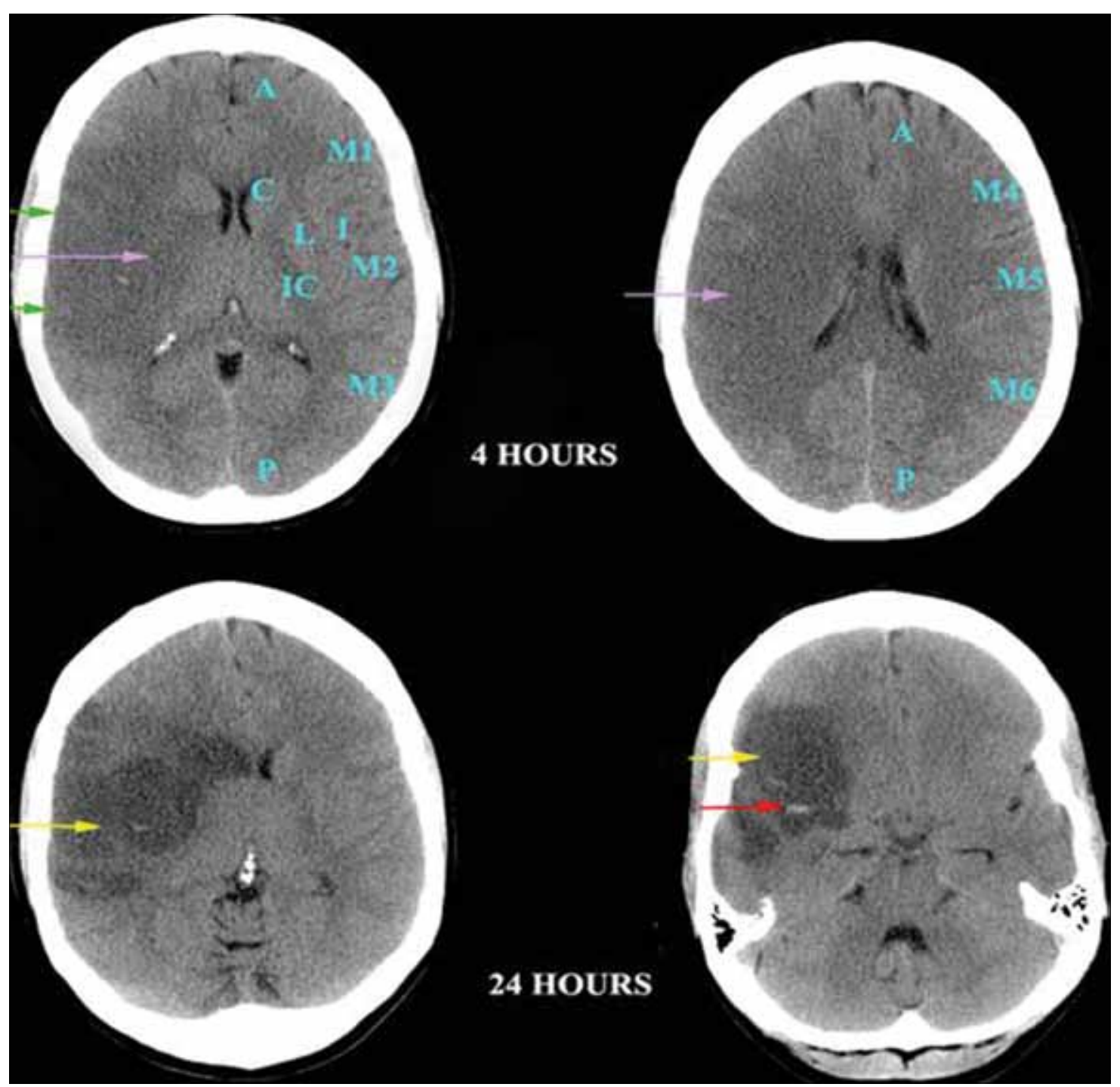

Figure 1: CCT brain of patient with right MCA infarct. EIC evident at $4 \mathrm{~h}$ after onset are sulcal effacement (green arrow), parenchymal hypoattenuation (purple arrow). (C-caudate, L-lentiform, IC-internal capsule, I-insular ribbon, MI-anterior MCA cortex, M2-MCA cortex lateral to insular ribbon, M3posterior MCA cortex, M4, M5, and M6 are anterior, lateral, and posterior MCA territories immediately superior to MI, M2, and M3, rostral to basal ganglia, A-anterior and P-posterior circulation). At $24 \mathrm{~h}$, parenchymal hypodensity (yellow arrow) and petechial hemorrhagic transformation (red arrow) 
The Alberta Stroke Program Early CT Score (ASPECTS) is a validated scale useful for assessing the extent of ischemic changes within the MCA territory [Figure 1]. ${ }^{[13]}$ It is a negative ordinal scale which scores normal brain as " 10 " and those with ischemic changes in the entire MCA territory as " 0 ". ASPECTS provides a formalized and systematic approach for the quantification of acute CT scans for ischemic changes. The inter-rater agreement is satisfactory, especially when used by experienced stroke neurologists, and the sensitivity for detection of early ischemic changes is higher than that of the onethird rule. ${ }^{[14,15]}$ Another potential advantage of ASPECTS in providing prognostic information, is that it gives equal weight to both larger volumes and smaller, but functionally important sub-cortical structures including basal ganglia and the internal capsule.

NCCT does not permit optimal evaluation of the posterior circulation (PC) ischemic stroke. A version of the ASPECT score has been developed for assessment of the posterior circulation (PC-ASPECTS). This is also a negative ordinal scale that allots 10 points to the posterior circulation ( 2 points are allotted to the midbrain and pons, and 1 each to left or right thalamus, cerebellum or occipital cortex). In contrast to the MCA territory ASPECT score, the sensitivity of PC-ASPECTS for identification of EIC on NCCT is less than $50 \%$ and the score does not correlate with stroke outcome in patients with vertebrobasilar ischemia or basilar artery occlusion. ${ }^{[16]}$

Assessment of NCCT scans using ASPECTS in the National Institute of Neurological Disorders and Stroke NINDS dataset showed that baseline ischemic changes did not have a treatment-modifying effect within the $3 \mathrm{~h}$ time window. ${ }^{[17]}$ Other studies have indicated that the extent of ischemic changes on CT do predict the response to thrombolysis administered more than $3 \mathrm{~h}$ after symptom onset. Dichotomization of the ASPECT scores to $\leq 7$ or $>7$, in patients imaged more than $3 \mathrm{~h}$ after symptom onset, appears to have some prognostic value. A score of $>7$ is predictive of improved outcome following thrombolysis, while patients with scores $\leq 7$ have a higher risk of hemorrhagic transformation and are less likely to benefit from treatment. ${ }^{[8,9,17]}$ The risk of hemorrhagic transformation is also dependent on time to imaging and the extent of reperfusion, making it impossible to predict on the basis of CT changes alone.

While ASPECT scores and the one-third MCA rule do not distinguish between hypoattenuation and swelling, the pathophysiological substrate underlying these changes is clearly different. ${ }^{[18]}$ Comparison of early ischemic changes on CT with magnetic resonance imaging/positron emission tomography (MRI/PET) studies reveals that hypoattenuated areas have decreased cerebral blood volume, restricted diffusion, increased tissue water content, and are destined to infarct. ${ }^{[19-21]}$ Isolated focal swelling or sulcal effacement, has been shown to represent a compensatory increase in cerebral blood volume (CBV). It can therefore be viewed as a marker of penumbral tissue, although it is not observed frequently enough to be relied upon as a treatment selection tool. Conversely, tissue with isolated sulcal effacement and no hypoattenuation is metabolically active and potentially salvageable with reperfusion therapies. ${ }^{[18,21,22]}$

Despite its shortcomings, NCCT imaging is still the most widely used modality for selection of patients for reperfusion therapy. It has the advantages of wide availability, short acquisition time and a high sensitivity for identification of intracranial hemorrhage. NCCT demonstrates areas of irreversible infarction, but in most cases provides little insight into the presence or extent of penumbral tissue. Fortunately, more advanced CT-based imaging techniques can be used to gain additional pathophysiological information.

\section{Imaging Blood Vessels: Computed Tomographic Angiography}

Computed tomographic angiography (CTA) utilizes spiral CT in combination with IV iodinated contrast to evaluate the head and neck vessels. It is noninvasive, permits rapid assessment of cerebral vessels, and can be done in conjunction with NCCT or even CT perfusion. Multi-detector helical scanners have decreased scanning times and radiation exposure, minimizing the risk of this procedure. Thin section imaging is performed during intravascular passage of a bolus of contrast media. The quality of imaging is dependent on patient physiology, contrast injection parameters and scan acquisition time. The amount of contrast used can vary depending on patient physiology (weight, hemodynamic parameters, contrast excretion) and the scan time. ${ }^{[23]}$ Typically, $100-140 \mathrm{ml}$ of iodinated contrast (140 to $350 \mathrm{mg} / \mathrm{ml}$ ) is used. Lower volumes of contrast and/or lower concentration (isosmolar) contrast can also be used in patients with renal impairment. ${ }^{[2]]}$ For adequate vascular opacification, contrast is administered intravenously as a rapid bolus infusion. The optimum bolus shape (vascular density versus time, at a region of interest) is a rapid rise, plateau of peak enhancement, followed by a rapid fall. Use of a bolus-chaser (saline injection following contrast bolus) or novel injector techniques e.g. exponentially decelerated injection method, provide near-optimal bolus shape. ${ }^{[25]}$ The optimal timing of scan acquisition following contrast bolus may be identified using test-bolus injections or bolus-triggered scanning can be used to maximize image quality. ${ }^{[26]}$ 
CTA rapidly permits an accurate assessment of the extracranial and intracranial vasculature. A combined aortic arch to cranial vertex protocol can image the entire cerebrovascular axis within $15 \mathrm{sec} .{ }^{[27]}$ This protocol will often identify acute occlusions resulting in ischemic stroke and also provide etiological information, including potential proximal embolic sources (atheromatous lesions, arterial dissection, aneurysms and thrombi). The accuracy of identifying large vessel occlusion and $\geq 50 \%$ stenosis is greater than $95 \% .{ }^{[28]}$ Smaller intracranial vessel occlusion or stenosis, including those arteries beyond the second division of the MCA, are less reliably visualized. ${ }^{[28]}$

Thrombi in large vessels are identified as irregular filling defects on CTA, which may be complete (i.e. no flow) or partial [Figure 2]. Atherosclerotic plaques can be seen as luminal irregularity and stenosis or occlusion. ${ }^{[29]}$ Delayed image acquisition can accurately distinguish critical stenosis from total occlusion by identifying streak/hairline-flow, which is critical in determining the need for surgical intervention. Though CTA source images can be used to identify vessel occlusions in most cases, short segment or partial occlusions may be missed, especially in areas of tortuous or overlapping vessels. Three-dimensional reconstruction provides high-resolution angiographic images of the vascular tree. Reconstruction requires additional time for postacquisition processing, however. Maximum intensity projection (MIP) images in the axial, sagittal and coronal planes can be constructed from all pixels with the highest density at any point during the acquisition, forming a two-dimensional blood vessel image. A MIP image can be used to quickly identify abnormalities in the circle of Willis. However, MIP images can be obscured by

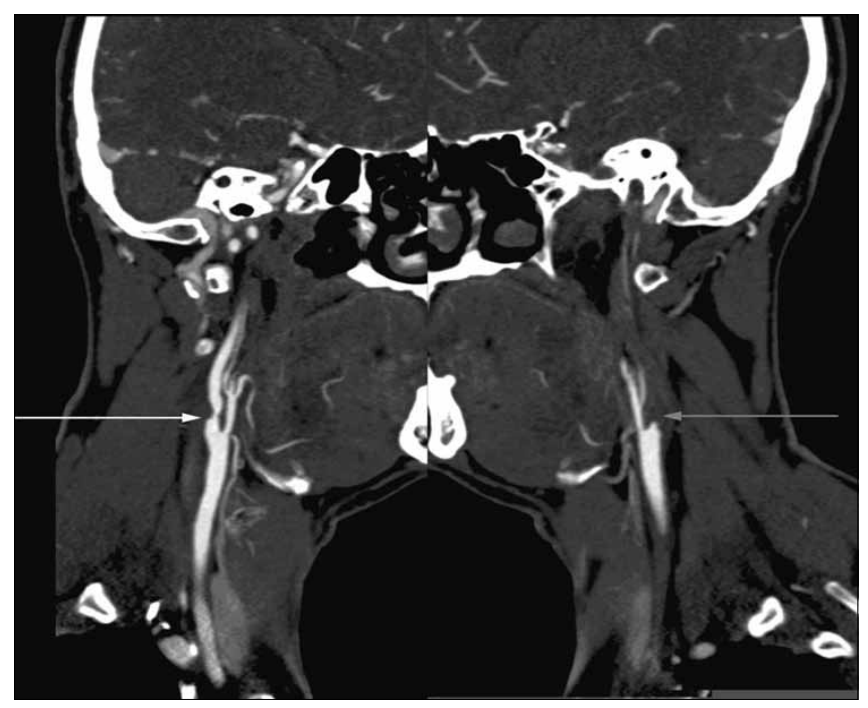

Figure 2: Computed tomography angiography (maximal intensity projections) from a patient with left internal carotid artery occlusion (complete cutoff of the vessel; grey arrow) and right internal carotid artery stenosis (filling defect; white arrow) overlying high-density structures, like the base of skull or extensive vascular calcification and reference to the source images is recommended. ${ }^{[30]}$ Heavy calcification in vessels can occasionally lead to inaccurate estimation of residual lumen diameter by CTA. ${ }^{[2]}$ This is most relevant when assessing the extracranial internal carotid artery for stenosis.

CTA source images (SI) can also provide information about the quality of the collateral circulation in acute ischemic stroke. The extent of perilesional intravascular enhancement is considered a surrogate marker for the leptomeningeal collateral flow and areas with a low CBV appear unenhanced. ${ }^{[31]}$ Patients with good collateral circulation, as assessed on CTA-SI, have better clinical outcomes than those with poor collaterals ${ }^{[32]}$ It has also been demonstrated that ASPECTS can be applied to CTASI (regions with relatively decreased contrast enhancement are scored as abnormal). ${ }^{[33,34]}$ Low ASPECT scores on CTASI predict final infarct volume more accurately than NCCT ASPECTS. ${ }^{[34]}$ Lesions on CTA-SI have also been shown to have excellent correlation with regions of restricted diffusion on MRI DWI (diffusion weighted imaging). ${ }^{[3,34]}$ Thus, CTA-SI can be used to rapidly estimate the extent of the ischemic core in the acute setting.

\section{Imaging Cerebral Blood Flow: Computed Tomographic Perfusion}

Using standard non-ionic iodinated contrast, the transit of a bolus of intravenous media can be traced by its serial effect on X-ray hypoattenuation. ${ }^{[35]}$ Following a contrast bolus (40-50 $\mathrm{ml}$ of iodinated contrast), one or multiple $\mathrm{CT}$ slices are acquired at fixed time intervals. The change in signal intensity, measured in Hounsfield units, after contrast media injection is proportional to the density of tissue and therefore the concentration of contrast at each time point. In this way, time density curves can be generated for each voxel. Maps of perfusion can then be derived from the tissue-time density curve, based on the central volume principle. Maps of regional (r) $\mathrm{CBV}, \mathrm{CBF}$, time to peak (TTP) and mean transit time (MTT) can be generated from the tissue-time density curves [Figure 3]. CBF is proportional to the amplitude of the curve and CBV to the area under the curve. MTT, which is prolonged in ischemia, can be estimated as a ratio of $\mathrm{CBV} / \mathrm{CBF}$. As the relationship between iodinated contrast density and concentration is linear, quantitative flow estimates are possible, which is a theoretical advantage over current MRI-based perfusion techniques. Quantitative measures of flow are obtained by scaling relative values on a voxel-wise basis to the intensity obtained from a voxel at the centre of the superior sagittal venous sinus (in which the partial 


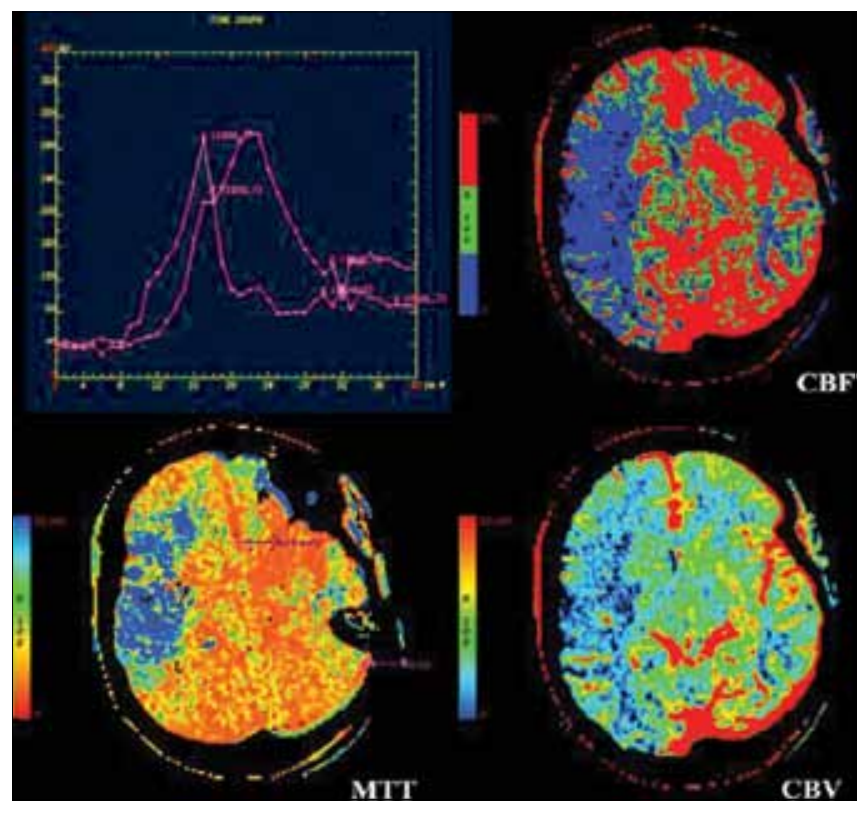

Figure 3: Computed tomography perfusion in a patient with acute right middle cerebral artery stroke. Top left: Time-density curves from artery (used for deconvolution) and vein (used to scale maps). Calculated perfusion maps include cerebral blood flow, mean transit time and cerebral blood volume. There is decreased CBF, prolonged MTT and decreased CBV in the right MCA territory, consistent with acute ischemia. The area of low CBV is similar in size, i.e. matched, to the tissue where MTT is prolonged/CBF is reduced, consistent with a nonpenumbral pattern

volume effect is absent, and is assumed to give a CBV value of $104 \mathrm{ml} / 100 \mathrm{~g}){ }^{[35]}$ Inaccuracies in flow estimation result from contrast delay and dispersion. Deconvolution of the parenchymal time-concentration curves, using a reference arterial input curve can be performed in order to provide a mathematical approximation of the effect of an instantaneous injection of contrast. ${ }^{[36]}$ Using deconvolution, CTP measures of CBF are in agreement with flow values obtained with PET. ${ }^{[37]}$

CTA and CTP sequences can be performed immediately following NCCT, adding only few minutes to the total exam time. The information provided by multimodal CT imaging in acute stroke patients demonstrates excellent correlation with the data obtained from MRI studies. ${ }^{[38]}$ The multimodal stroke assessment using CT (MOSAIC) score is a combination of ASPECTS and information provided by CTA and CTP (CBF assessed in two slices) ${ }^{[39]}$ In comparison to single CT components, it shows a superior correlation with the final infarct volume and clinical outcome. ${ }^{[39]}$ The Boston Acute Stroke Imaging Scale for classification of acute ischemic stroke utilizes CTA (or magnetic resonance angiography, MRA) and the evaluation of cerebral parenchyma by NCCT (or MRI). It is superior to NCCTASPECTS alone in identifying patients with a high likelihood of a poor outcome. ${ }^{[40]}$

\section{The Mismatch Hypothesis}

Advanced CT imaging techniques can provide visual representations of both tissue at risk and irreversibly injured infarct core regions. By combining these images, it is therefore also possible to develop an operational definition of the ischemic penumbra. An imbalance in the volume of hypoperfused versus core infarct tissue is referred to as a 'mismatch' pattern, the presence of which may theoretically indicate an enriched response to tissue salvage therapies, in particular thrombolysis.

\section{Computed tomography perfusion-defined mismatch}

CT perfusion-derived TTP, Tmax, MTT and CBF maps all demonstrate hypoperfused areas at risk for infarction. Ischemic core tissue can be demonstrated using NCCT (hypoattenuation) or with CBV maps. Areas of low CBV represent irreversibly injured tissue, where compensatory vasodilatation in response to oligemia has failed. The ischemic penumbra is therefore represented by tissue where MTT is prolonged, and CBF is decreased, but CBV is normal (CBF-CBV mismatch or MTT-CBV mismatch) ${ }^{[41]}$ The mismatch between MTT and CBV abnormalities on CTP correlates well with MRI-based penumbral definitions. ${ }^{[42]}$

Refinements to the mismatch hypothesis have been made using CT perfusion thresholds. Penumbral and infarct regions have been identified on the basis of MTT and CBV thresholds. Wintermark et al., defined ischemic areas as those with MTT prolongation greater than $145 \%$ of the normal contralateral hemisphere and infarct core as tissue with $\mathrm{rCBV}<2 \mathrm{ml} / 100 \mathrm{~g}$. ${ }^{[41]}$ The optimal mismatch definitions and perfusion deficit thresholds are still unknown, as they likely vary with the duration of ischemia. ${ }^{[43]}$ However, the use of CTP with thresholds provides a more accurate estimate of penumbra and the final infarct volume compared to CTA-SI. ${ }^{[44]}$ It has also been demonstrated that ASPECTS scores can be applied to $\mathrm{CT}$ perfusion images, providing a semi-quantitative estimate of penumbral tissue volume and also predicting neurological improvement. ${ }^{[45]}$

\section{Ct Based Imaging Based Prediction of tPA Related Bleeding Risk}

Intracerebral hemorrhage is the most feared complication of rtPA use in acute stroke and is associated with worse clinical outcome and elevated mortality rates. ${ }^{[46]}$ Identification of predictors of intracranial hemorrhage (ICH) following thrombolytic therapy is necessary for safe implementation of thrombolysis. ICH following thrombolytic therapy has been classified as hemorrhagic 
transformation (HT), defined as petechiae which may or may not be within the ischemic lesion, and parenchymal hemorrhage $(\mathrm{PH})$, which refers to a hematoma with space-occupying effect. ${ }^{[4]} \mathrm{HT}$ is thought to be a marker of reperfusion into ischemic tissue with microvascular damage, without any adverse clinical impact. ${ }^{[48]}$ However, one retrospective study has indicated that HT may have some adverse effects. ${ }^{[49]}$ This subject requires further prospective studies, in large patient populations.

Most thrombolysis studies have defined symptomatic $\mathrm{ICH}$ as any sign of hemorrhage on post-treatment imaging ( $36 \mathrm{~h}$ to one week) associated with clinical deterioration, indicated by an increase of 4 points or more on the NIHSS scale. ${ }^{[50,51]}$ In the NINDS trials, extensive cerebral edema (ischemic changes in more than one-third MCA) present on baseline CT scans was seen more frequently in patients with ICH $(9 \%$ vs. $4 \%$ in whole of the remainder of study population) ${ }^{[52]}$ Another post-hoc CT analysis of the NINDS data, however, showed that, after adjustment for the baseline NIHSS, early ischemic changes (loss of grey/white matter distinction, hypoattenuation, hypodensity, compression of CSF Cerebrospinal fluid spaces) were not associated with "symptomatic" ICH. ${ }^{[53]}$ An analysis of baseline CTs in the European-Australian Acute Stroke Study (ECASS) II study showed that patients with ASPECTS score $\leq 7$ have a higher risk of $\mathrm{PH}$ after thrombolytic therapy (rTPA within a $6 \mathrm{~h}$ time window), relative to those with scores $>7{ }^{[8,9]}$ Tanne et al., evaluated data from 1205 patients, thrombolysed within $6 \mathrm{~h}$ of stroke onset and found that the severity of early ischemic changes predicted the risk of developing parenchymal hematomas following treatment. ${ }^{[54]}$ Whether the extent of early ischemic changes on CT justifies exclusion of patients from thrombolysis is still debatable. While both hypoattenuation and swelling are included in early ischemic changes, the pathophysiological substrate underlying these changes is not the same, and may have a differential effect on the risk of hemorrhage.

Hemorrhagic transformation, both spontaneous and tPA related, remains difficult to predict. It is unlikely that any single imaging parameter will reliably predict hemorrhagic risk. This is because symptomatic hemorrhage occurs in relatively few patients, even in the tPA-treated population (5-8\%). ${ }^{[55,56]}$ In addition, the development of hemorrhage is most certainly multifactorial, being dependent not only on the extent of parenchymal changes, but also on reperfusion, hypertension, glycemic control and other uncharacterized susceptibility differences that vary between individual patients. ${ }^{[57,58]}$

\section{Advanced Imaging in Intracerebral Hemorrhage}

$\mathrm{CT}$ remains the imaging modality of choice to diagnose intracerebral bleeds in most clinical settings. Acute blood is readily identifiable on CT as areas of hyperdensity, with or without surrounding edema. Following the acute phase, the blood constituents are metabolized and reabsorbed. In the chronic phase, hemorrhage cannot be differentiated from ischemic lesions as only a hypodense cavity remains as a marker of the preceding lesion.

\section{Computed tomographic angiography and intracerebral hemorrhage}

CTA has a high sensitivity and specificity for the identification of a source (AVMarteriovnous malformation/aneurysm) of secondary parenchymal $\mathrm{ICH}$ or subarachnoid bleeds. For aneurysms $>2 \mathrm{~mm}$ in size, the sensitivity is $\sim 95 \%$; for smaller aneurysms the sensitivity is approximately $50 \%{ }^{[10,59]}$ Occasionally, infundibular dilatation of an artery origin may be incorrectly identified as an aneurysm. ${ }^{[60]}$ Although DSA(digital subtraction angiography) provides superior information on blood flow patterns and visualization of small vessels, CTA is cost-effective and can be easily performed immediately following NCCT in the acute setting.

Contrast extravasation on contrast-enhanced CT or CTA (source images) has been shown to be an independent predictor of hematoma expansion and mortality following ICH. ${ }^{[61,62]}$ The CTA (source images) "spot sign", defined as small foci of enhancement within a parenchymal hematoma, has been observed in 30-50\% of patients imaged within $3 \mathrm{~h}$ of onset of spontaneous $\mathrm{ICH}(\mathrm{sICH}) .{ }^{[63,64]} \mathrm{It}$ is absent in patients with secondary $\mathrm{ICH}$, and may be specific for sICH. However, calcific deposits, thrombosed aneurysm or micro-arteriovenous malformation and tumor can be potentially confounding mimics of the spot sign. ${ }^{[65]}$

Increased blood-brain barrier permeability, has recently been shown to be a predictor of hemorrhage following thrombolysis. In a rat model of stroke, early parenchymal enhancement (gadolinium MRI) was found to predict hemorrhage following reperfusion. ${ }^{[66]} \mathrm{Lin}$ et al., used PCTperfusion CT to evaluate microvascular permeability in patients with acute ischemic stroke. Patients showing increased permeability in the ischemic areas were more likely to develop petechial hemorrhages (non-thrombolyzed patients) and parenchymal hematomas (thrombolysed patients) ${ }^{[67]}$ Presence of early parenchymal enhancement on post-thrombolytic $(\sim 2 \mathrm{~h})$ contrast-enhanced MRI has also been shown to predict hemorrhagic transformation. ${ }^{[68,69]}$ 
At present, NCCT remains the imaging modality of choice for thrombolysis patient selection in most centers. Advanced CT techniques do have some disadvantages, including increased radiation exposure, contrastrelated complications, low sensitivity for lacunar/small deep infarcts ${ }^{[70]}$ and limited brain coverage. Increased radiation dosage and contrast-related complications are a consideration when using advanced CT imaging techniques. Depending on scan parameters used, radiation doses of 5-10 mSv are used for a multimodal CT exam, making multiple examinations less desirable. Contrast-related renal complications are now not very frequent $(3.3 \%)$, and are mostly limited to mild reversible nephropathy. An important limitation of current scanners is the limited sampling volume, but this is improving. Most scanners currently in operation have columnation widths of $1-4 \mathrm{~cm}$. Thus, it is possible that areas of hypoperfusion may not be recognized in acute stroke patients imaged with this technique. Newer scanners, using 256 detector rows, have been developed that provide up to $8 \mathrm{~cm}$ of coverage and permit simultaneous CTA acquisition using a single bolus of contrast media. CTA and CTP are under-utilized in our opinion; they do increase the diagnostic yield substantially over NCCT alone and can be performed with minimal delay. Advanced CT imaging should be utilized more both in clinical practice and future clinical stroke trials. In the second part of this series, the utility of MRI in acute stroke management will be examined.

\section{References}

1. Richmond C. Obituary - Sir Godfrey Hounsfield. BMJ 2004:329:687.

2. Hacke W, Donnan G, Fieschi C, Kaste M, von Kummer R, Broderick JP, et al. Association of outcome with early stroke treatment: Pooled analysis of ATLANTIS, ECASS, and NINDS rt-PA stroke trials. Lancet 2004;363:768-74.

3. Astrup J, Siesjo BK, Symon L. Thresholds in cerebral ischemia-the ischemic penumbra. Stroke 1981;12:723-5.

4. von Kummer R. Early major ischemic changes on computed tomography should preclude use of tissue plasminogen activator. Stroke 2003;34:820-1.

5. von Kummer R, Nolte PN, Schnittger H, Thron A, Ringelstein EB. Detectability of cerebral hemisphere ischemic infarcts by CT within $6 \mathrm{~h}$ of stroke. Neuroradiology 1994;38:31-3.

6. Horowitz SH, Zito JL, Dinnarumma R, Patel M, Alvir J. Computed tomographic-angiographic findings within the first five hours of cerebral infarction. Stroke 1991;22:1245-53.

7. Rajajee V, Kidwell C, Starkman S, Ovbiagele B, Alger J, Villablanca P, et al. Diagnosis of lacunar infarcts within 6 hours of onset by clinical and CT criteria versus MRIJ Neuroimaging 2008;18:66-72.

8. Hill MD, Rowley HA, Adler F, Eliasziw M, Furlan A, Higashida RT, et al. Selection of acute ischemic stroke patients for intra-arterial thrombolysis with pro-urokinase by using ASPECTS. Stroke 2003;34:1925-31.

9. Dzialowski I, Hill MD, Coutts SB, Demchuk AM, Kent DM, Wunderlich O, von Kummer R. Extent of early ischemic changes on computed tomography (CT) before thrombolysis: Prognostic value of the Alberta Stroke Program Early CT Score in ECASS II. Stroke 2006;37:973-8.

10. Aronovich BD, Reider-Groswasser II, Segev Y, Bornstein NM. Early CT changes and outcome of ischemic stroke. Eur J Neurol 2004;11:63-5.

11. Marks MP, Holmgren EB, Fox AJ, Patel S, von Kummer R, Froehlich J.
Evaluation of early computed tomographic findings in acute ischemic stroke. Stroke 1999;30:389-92.

12. Dávalos A, Toni D, Iweins F, Lesaffre E, Bastianello S, Castillo J. Neurological deterioration in acute ischemic stroke: Potential predictors and associated factors in the European cooperative acute stroke study (ECASS) I. Stroke 1999;30:2631-6.

13. Barber PA, Demchuk AM, Zhang J, Buchan AM. Validity and reliability of a quantitative computed tomography score in predicting outcome of hyperacute stroke before thrombolytic therapy. Lancet 2000;355:1670-4.

14. Demaerschalk BM, Silver B, Wong E, Merino JG, Tamayo A, Hachinski V. ASPECT scoring to estimate $>1 / 3$ middle cerebral artery territory infarction. Can J Neurol Sci 2006;33:200-4.

15. Mak HK, Yau KK, Khong PL, Ching AS, Cheng PW, Au-Yeung PK, et al. Hypodensity of $>1 / 3$ middle cerebral artery territory versus alberta stroke programme early CT score (ASPECTS): Comparison of two methods of quantitative evaluation of early $\mathrm{CT}$ changes in hyperacute ischemic stroke in the community setting. Stroke 2003;34:1194-6.

16. Puetz V, Sylaja PN, Coutts SB, Hill MD, Dzialowski I, Mueller P, et al. Extent of hypoattenuation on CT angiography source images predicts functional outcome in patients with basilar artery occlusion. Stroke 2008;39:2485-90.

17. Demchuk AM, Hill MD, Barber PA, Silver B, Patel SC, Levine SR; NINDS rtPA Stroke Study Group, NIH. Importance of early ischemic computed tomography changes using ASPECTS in NINDS rtPA Stroke Study. Stroke 2005;36:2110-5.

18. Butcher KS, Lee SB, Parsons MW, Allport L, Fink J, Tress B, et al. Differential prognosis of isolated cortical swelling and hypoattenuation on CT in acute stroke. Stroke 2007;38:941-7.

19. Barber PA, Darby DG, Desmond PM, Gerraty RP, Yang Q, Li T, et al. Identification of major ischemic change: Diffusion weighted imaging versus computed tomography. Stroke 1999;30:2059-65.

20. Grond M, von Kummer R, Sobesky J, Schmulling S, Rudolf J, Terstegge K, Heiss W. Early X-ray hypoattenuation of brain parenchyma indicates extended critical hypoperfusion in acute stroke. Stroke 2000;31:133-9.

21. Muir KW, Baird-Gunning J, Walker L, Baird T, McCormick M, Coutts SB. Can the Ischemic Penumbra Be Identified on Noncontrast CT of Acute Stroke? Stroke 2007;38:2485-90.

22. Na DG, Kim EY, Ryoo JW, Lee KH, Roh HG, Kim SS, Song IC, Chang KH. Ct sign of brain swelling without concomitant parenchymal hypoattenuation: Comparison with diffusion- and perfusion-weighted MR imaging. Radiology 2005;235:992-48.

23. Cademartiri F, van der Lugt A, Luccichenti G, Pavone P, Krestin GP. Parameters affecting bolus geometry in CTA: A review. J Comput Assist Tomogr 2002;26:598-607.

24. Thomsen HS, Morcos SK. Contrast media and the kidney: European society of urogenital radiology (ESUR) guidelines. Br J Radiol 2003;76:513-8

25. Bae KT, Heiken JP, Brink JA. Aortic and hepatic peak enhancement at CT: Effect of contrast medium injection rate pharmacokinetic analysis and experimental porcine model. Radiology 1998;206:455-64.

26. Schoellnast H, Tillich M, Deutschmann MJ, Schaffler GJ, Portugaller HR. Aortoiliac enhancement during computed tomography angiography with reduced contrast material dose and saline solution flush: Influence on magnitude and uniformity of the contrast column. Invest Radiol 2004;39:20-6.

27. Pomerantz SR, Harris G.J, Desai HJ, Lev MH. Computed tomography angiography and computed tomography perfusion in ischemic stroke: A step-by-step approach to image aequisition and three-dimensional post processing. Semin Ultrasound CT MR 2006;27:243-70.

28. Nguyen-Huynh MN, Wintermark M, English J, Lam J, Vittinghoff $\mathrm{E}$, Smith WS, et al. How accurate is CT angiography in evaluating intracranial atherosclerotic disease? Stroke 2008;39:1184-8.

29. Forsting M. CTA of the ICA bifurcation and intracranial vessels. Eur Radiol 2005;15: D25-7.

30. Gratama van Andel HA, Venema HW, Streekstra GJ, van Straten M, Majoie CB, den Heeten GJ, et al. Removal of bone in CT angiography by multiscale matched mask bone elimination. Med Phys 2007;34:3711-23.

31. Ezzeddine MA, Lev MH, McDonald CT, Rordorf G, Oliveira-Filho J, 
Aksoy FG, et al. CT angiography with whole brain perfused blood volume imaging: Added clinical value in the assessment of acute stroke. Stroke 2002;33:959-66.

32. Schramm P, Schellinger PD, Fiebach JB, Heiland S, Jansen O, Knauth M, et al. Comparison of CT and CT angiography source images with diffusion-weighted imaging in patients with acute stroke within 6 hours after onset. Stroke 2002;33:2426-32.

33. Schramm P, Schellinger PD, Klotz E, Kallenberg K, Fiebach JB, Külkens $\mathrm{S}$, et al. Comparison of perfusion computed tomography and computed tomography angiography source images with perfusionweighted imaging and diffusion-weighted imaging in patients with acute stroke of less than 6 hours' duration. Stroke 2004;35:1652-8.

34. Coutts SB, Lev MH, Eliasziw M, Roccatagliata L, Hill MD, Schwamm LH, et al. ASPECTS on CTA source images versus unenhanced CT: Added value in predicting final infarct extent and clinical outcome. Stroke 2004;35:2472-6.

35. Wintermark M, Maeder P, Thiran JP, Schnyder P, Meuli R. Quantitative assessment of regional cerebral blood flows by perfusion CT studies at low injection rates: A critical review of the underlying theoretical models. Eur Radiol 2001;11:1220-30.

36. Eastwood JD, Lev MH, Azhari T, Lee TY, Barboriak DP, Delong DM, et al. CT perfusion scanning with deconvolution analysis: Pilot study in patients with acute middle cerebral artery stroke. Radiology 2002;222:227-36.

37. Kudo K, Terae S, Katoh C, Oka M, Shiga T, Tamaki N, et al. Quantitative cerebral blood flow measurement with dynamic perfusion CT using the vascular-pixel elimination method: Comparison with $\mathrm{H} 2(15) \mathrm{O}$ positron emission tomography. Am J Neuroradiol 2003;2:419-26.

38. Wintermark M, Meuli R, Browaeys P, Reichhart M, Bogousslavsky J, Schnyder $\mathrm{P}$, et al. Comparison of CT perfusion and angiography and MRI in selecting stroke patients for acute treatment. Neurology 2007;68:694-7.

39. Nabavi DG, Kloska SP, Nam EM, Freund M, Gaus CG, Klotz E, et al.MOSAIC: Multimodal Stroke Assessment Using Computed Tomography: Novel diagnostic approach for the prediction of infarction size and clinical outcome. Stroke 2002;33:2819-26.

40. Torres-Mozqueda F, He J, Yeh IB, Schwamm LH, Lev MH, Schaefer PW, et al. An acute ischemic stroke classification instrument that includes CT or MR angiography: The Boston Acute Stroke Imaging Scale. AJNR Am J Neuroradiol 2008;29:1111-7.

41. Wintermark M, Reichhart M, Thiran JP, Maeder P, Chalaron M, Schnyder P, et al. Prognostic accuracy of cerebral blood flow measurement by perfusion computed tomography, at the time of emergency room admission, in acute stroke patients. Ann Neurol 2002;51:417-32.

42. Wintermark M, Reichhart M, Cuisenaire O, Maeder P, Thiran JP, Schnyder $\mathrm{P}$, et al. Comparison of admission perfusion computed Tomography and qualitative perfusion and diffusion weighted magnetic resonance imaging in acute stroke patients. Stroke 2002;33:2025-31.

43. Butcher KS, Parsons MW, Davis S, Donnan G. PWI/DWI mismatch: Better definition required. Stroke 2003;34: E215-6.

44. Parsons MW, Pepper EM, Chan V, Siddique S, Rajaratnam S, Rajarabram S, et al. Perfusion computed tomography: Prediction of final infract extent and stroke outcome. Ann Neurol 2005;58:672-9.

45. Aviv RI, Mandelcorn J, Chakraborty S, Gladstone D, Malham S, Tomlinson G, et al. Alberta Stroke Programme Early CT Scoring of CT perfusion in early stroke visualization and assessment. Am J Neuroradiol 2007;28:1975-80.

46. Berger C, Fiorelli M, Steiner T, Schäbitz WR, Bozzao L, Bluhmki E, et al. Hemorrhagic transformation of ischemic brain tissue: Asymptomatic or symptomatic? Stroke 2001;32:1330-5.

47. Larrue V, von Kummer RR, Muller A, Bluhmki E. Risk factors for severe hemorrhagic transformation in ischemic stroke patients treated with recombinant tissue plasminogen activator: A secondary analysis of the european-australasian acute stroke study (ECASS II). Stroke 2001;32:438.

48. Hamann GF, del Zoppo GJ, von Kummer R. Hemorrhagic transformation of cerebral infarction-possible mechanisms. Thromb Haemost 1999;82:92-4.

49. Dzialowski I, Pexman JH, Barber PA, Demchuk AM, Buchan AM,
Hill MD et al. Asymptomatic hemorrhage after thrombolysis may not be benign: Prognosis by hemorrhage type in the Canadian alteplase for stroke effectiveness study registry. Stroke 2007;38:75-9.

50. Davis SM, Donnan GA, Parsons MW, Levi C, Butcher KS, Peeters A, et al. Effects of alteplase beyond $3 \mathrm{~h}$ after stroke in the Echoplanar Imaging Thrombolytic Evaluation Trial (EPITHET): A placebocontrolled randomised trial. Lancet Neurol 2008;7:299-309.

51. Furlan A, Higashida R, Wechsler L, Gent M, Rowley H, Kase C, et al. Intra-arterial prourokinase for acute ischemic stroke. The PROACT II study: A randomized controlled trial. Prolyse in acute cerebral thromboembolism]. JAMA 1999;282:2003-11.

52. Tissue plasminogen activator for acute ischemic stroke. The National Institute of Neurological Disorders and Stroke rt-PA Stroke Study Group. N Engl J Med 1995;333:1581-7.

53. Patel SC, Levine SR, Tilley BC, Grotta JC, Lu M, Frankel M, et al. Lack of clinical significance of early ischemic changes on computed tomography in acute stroke. JAMA 2001;286:2830-8.

54. Tanne D, Kasner SE, Demchuk AM, Koren-Morag N, Hanson S, Grond M, et al. Markers of increased risk of intracerebral hemorrhage after intravenous recombinant tissue plasminogen activator therapy for acute ischemic stroke in clinical practice: The Multicenter rt-PA Stroke Survey. Circulation 2002;105:1679-85.

55. Thomalla G, Schwark C, Sobesky J, Bluhmki E, Fiebach JB, Fiehler J, et al. Outcome and symptomatic bleeding complications of intravenous thrombolysis within 6 hours in MRI-selected stroke patients: Comparison of a German multicenter study with the pooled data of ATLANTIS, ECASS, and NINDS tPA trials. Stroke 2006;37:852-8.

56. Nadeau JO, Shi S, Fang J, Kapral MK, Richards JA, Silver FL, et al. TPA use for stroke in the Registry of the Canadian Stroke Network. Can J Neurol Sci 2005;32:433-9.

57. Wahlgren N, Ahmed N, Eriksson N, Aichner F, Bluhmki E, Dávalos A, et al. Multivariable analysis of outcome predictors and adjustment of main outcome results to baseline data profile in randomized controlled trials: Safe Implementation of Thrombolysis in Stroke-Monitoring Study (SITS-MOST). Stroke 2008;39:3316-22.

58. Larrue V, von Kummer RR, Müller A, Bluhmki E. Risk factors for severe hemorrhagic transformation in ischemic stroke patients treated with recombinant tissue plasminogen activator: A secondary analysis of the European-Australasian Acute Stroke Study (ECASS II). Stroke 2001;32:438-41.

59. Villablanca JP, Martin N, Jahan R, Gobin YP, Frazee, Duckwiler G, et al. Volume rendered helical computerized tomography angiography in the detection and characterization of intracranial aneurysms. J Neurosurg 2000;93:254-64.

60. Ng SH, Wong HF, Ko SF, Lee CM, Yen PS, Wai YY, et al. CT angiography of intracranial aneurysms: Advantages and pitfalls. Eur J Radiol 1997;25:14-9

61. Goldstein JN, Fazen LE, Snider R, Schwab K, Greenberg SM, Smith EE, et al. Contrast extravasation on CT angiography predicts hematoma expansion in intracerebral hemorrhage. Neurology 2007;68:889-94.

62. Kim J, Smith A, Hemphill JC 3rd, Smith WS, Lu Y, Dillon WP, et al. Contrast extravasation on CT predicts mortality in primary intracerebral hemorrhage. AJNR Am J Neuroradiol 2008;29:520-5.

63. Wada R, Aviv RI, Fox AJ, Sahlas DJ, Gladstone DJ, Tomlinson G, et al. CT angiography "Spot sign" Predicts hematoma expansion in acute intracerebral hemorrhage. Stroke 2007;38:1257.

64. Goldstein JN, Fazen LE, Snider R, Schwab K, Greenberg SM, Smith EE, et al. Contrast extravasation on CT angiography predicts hematoma expansion in intracerebral hemorrhage. Neurology 2007;68:889-94.

65. Gazzola S, Aviv RI, Gladstone DJ, Mallia G, Li V, Fox AJ, et al. Vascular and nonvascular Mimics of the CT angiography "Spot Sign" in patients with secondary intracerebral hemorrhage. Stroke 2008;39:1177-83.

66. Knight RA, Barker PB, Fagan SC, Li Y, Jacobs MA, Welch KM. Prediction of impending hemorrhagic transformation in ischemic stroke using magnetic resonance imaging in rats. Stroke 1998;29:144-51.

67. Lin K, Kazmi KS, Law M, Babb J, Peccerelli N, Pramanik BK. Measuring elevated microvascular permeability and predicting hemorrhagic transformation in acute ischemic stroke using first- 
pass dynamic perfusion CT imaging. AJNR Am J Neuroradiol 2007;28:1292-8.

68. Hjort N, Wu O, Ashkanian M, Sølling C, Mouridsen K, Christensen S, et al. MRI detection of early blood-brain barrier disruption: Parenchymal enhancement predicts focal hemorrhagic transformation after thrombolysis. Stroke 2008;39:1025-8.

69. Kastrup A, Groschel K, Ringer TM, Redecker C, Cordesmeyer R, Witte OW, et al. Early disruption of the blood-brain barrier after thrombolytic therapy predicts hemorrhage in patients with acute stroke. Stroke 2008;39:2385-7.

70. Rajajee V, Kidwell C, Starkman S, Ovbiagele B, Alger J, Villablanca P, et al. Diagnosis of lacunar infarcts within 6 hours of onset by clinical and CT criteria versus MRI. J Neuroimaging 2008;18:66-72.

Accepted on 09-08-2009

Source of Support: Nil, Conflict of Interest: None declared. 